American Journal of Immunology 7 (4): 54-61, 2011

ISSN 1553-619X

(C) 2011 Science Publications

\title{
Leukemia and Therapy
}

\author{
${ }^{1}$ Alitheen, N.B., ${ }^{2}$ S.K. Yeap, \\ ${ }^{1}$ N.H. Faujan, ${ }^{1}$ W.Y. Ho, ${ }^{1}$ B.K. Beh and ${ }^{1}$ A.R. Mashitoh \\ ${ }^{1}$ Department of Cell and Molecular Biology, \\ Faculty of Biotechnology and Biomolecular Sciences, \\ Universiti Putra Malaysia, Serdang, Selangor 43300, Malaysia \\ ${ }^{2}$ Institute of Bioscience, Universiti Putra Malaysia, Serdang, Selangor 43300, Malaysia
}

\begin{abstract}
Problem statement: Leukemia is a cancer which linked intimately with the immune system. It is a group of heterogenous neoplastic disorder of white blood cells characterized by the uncontrolled proliferation and block in differentiation of hematopoeitic cells. Generally, leukemia can be classified into myeloid or lymphoid referring to the type of abnormal cell found most in the blood. Approach: Many drug discovery researches have utilized the leukemic cell lines to screen for their potential as chemotherapy agents for leukemia. Results: The understanding on the types of leukemia and current choice of chemotherapy drugs can help to select the best target cell lines to study and the most suitable chemotherapy drug as positive control. Conclusion/Recommendations: This review cover types of leukemia, current option of chemotherapy drugs and some potential cytotoxic and immunomodulatory natural products targeting leukemic cancer cell line.
\end{abstract}

Key words: Leukemia, therapy, cytotoxic, natural products

\section{INTRODUCTION}

Cancer is a heterogeneous group of diseases, characterized by uncontrolled growth of cell population (Gomathi and Thangaraj, 2010). Continuous division of these cells results in the formation and growth of tumors. Tumors are classified with reference to a number of criteria including their behavior, their appearances and their origins (Evans, 1991). Cancer cells escape from many of the normal homeostatic mechanism that control proliferation (Goodman, 2008).

Clinical experience indicates that there are two fundamental types of tumors, benign and malignant, which behave in different ways (Darnell et al., 1986). Benign tumors remain localized and do not spread to different part of body (Evans, 1991). Malignant tumors do not remain localized and encapsulated. They invade surrounding tissues, get into the body's circulating system and set up areas of proliferation away from the site of their original appearance (Darnell et al., 1986).

Most tumors contain alterations in both tumorsuppressor genes and oncogenes, suggesting that the lost of a tumor-suppressor genes function within a cell must be accompanied by the conversion or activation of proto-oncogenes into an oncogene before the cell becomes fully malignant (Becker et al., 2000). Proto- oncogenes and tumor-suppressor genes encode many kinds of proteins that help control cell growth and proliferation. Mutations in these genes can contribute to the development of cancer (Lodish et al., 2000).

Cancerous tumor is the disease of malignant tumors. Malignant tumors or cancer are aggregates of cells caused by a series of chromosomal changes. Cancer cells often differ from their normal neighbors by a host of specific phenotypic changes, such as rapid division rate, invasion of new cellular territories, high metabolic rate and altered shape. Transformation of normal cells to malignant cells may triggered by several factors including chemical exposure, viruses and radiations. It also can occur deliberately under cellular control during the processes such as meiosis or hypermutation (Alves et al., 2011; Lodish et al., 2000).

Cancers originate within a single cell. Hence, cancers can be classified by the type of cell in which it originates and by the location of the cell as carcinomas, adenocarcinomas, malignant melanoma, sarcomas, leukemias, lymphomas or teratocarcinomas. Carcinomas originate in epithelial cells. Adenocarcinomas originate from glandular epithelial tissue. Malignant melanoma arises in melanocytes, a pigmented epithelial cell. Sarcoma begins in the connective tissue of bone or muscle. Leukemias start in

Corresponding Author: Swee Keong Yeap, Institute of Bioscience, Universiti Putra Malaysia, 43400, Serdang, Selangor Malaysia Tel: +60389467471 Fax:+60389467510 
Am. J. Immunol., 7 (4): 54-61, 2011

the bone marrow stem cells. Lymphoma is a cancer originating in lymphatic tissue. Teratocarcinomas begin within germ cells (Evans, 1991).

Leukemia: Leukemia is a cancer which linked intimately with the immune system. It is a malignant hematopoietic disease characterized by an uncontrolled proliferation and block in differentiation of hematopoietic cells (Lee et al., 2007). These malignant cells can spread to the lymph nodes, spleen, liver and other tissues. Leukemia is broadly classified as acute or chronic referring to the type of cell affected and by the rate of cell growth and of myeloid or lymphoid according to the type of cell that is multiplying abnormally. Acute leukemia signifying rapidly progressing disease with a presence of immature, blast cells, while chronic leukemia, denotes slowly progressing disease with more mature and well-differentiated cells. Some chronic leukemia may transform into an acute phase as "blast crisis" (Leonard, 1998).

The leukemias are classified in accordance with silent pathological features of the abnormal excessive hemopoietic cells (Mughal and Goldman, 2003). They are four major subtypes of leukemia and several rare forms. The acute leukemias are divided into Acute Myeloid Leukemia (AML) and Acute Lymphocytic Leukemia (ALL). The chronic leukemias are divided into Chronic Myeloid Leukemia (CML) and Chronic Lymphocytic Leukemia (CLL). Other, rare types of leukemia include hairy cell leukemia, sezary cell leukemia, plasma cell leukemia, prolymphocytic leukemia and the leukemia phase of lymphoma (Ball and Kagan, 2007). According to Lee et al. (2007), leukemia might affect people of all ages.

\section{Type of leukemia:}

Acute Myeloid Leukemia (AML): Acute myeloid leukemia or Acute Myelogenous Leukemia (AML) is characterized by the malignant transformation of myeloid stem cells in the bone marrow, which are in capable of normal differentiation and maturation (Mughal and Goldman, 2003). This type of leukemia is also referred to as Acute Nonlymphocytic Leukemia (ANLL) because nonlymphoid cells are affected (Lowenberg et al., 1999). Since the normal hematopoiesis is organized hierarchically, the malignant transformation can occur at several levels. AML may arise in a stem cell capable of differentiating into cells of erythroid, granulocytic, monocytic and megakaryocytic lineages, or in a lineage-restricted stem cell (Mughal and Goldman, 2003). AML is most common between ages 63-65 years among adults (Lowenberg et al., 1999).
Table 1: French-American-British (FAB) classification of Acute Myeloid Leukemia

\begin{tabular}{ll}
\hline Designation & Description \\
\hline M0 & Undifferentiated leukemia \\
M1 & Acute myeloblastic leukemia with immature cells \\
M2 & Acute myeloblastic leukemia with some mature cells \\
M3 & Acute promyelocytic leukemia \\
M4 & Acute myelomonocytic leukemia \\
M5 & Acute monocytic leukemia \\
M6 & Erythroleukemia (immature red and white blood cells) \\
M7 & Acute megakaryocytic leukemia (immature platelets \\
& megakaryocytes) \\
\hline
\end{tabular}

Most patients with AML present with signs and symptoms arising from bone marrow failure and organ infiltration by leukemic cells. Occasionally, patients may present as a consequence of hyperleucostasis. The diagnosis of AML is made when more than $30 \%$ of blast cells (myeloblasts) are found in bone marrow or peripheral blood (Mughal and Goldman, 2003). This results in anemia, thrombocytopenia and granulocytopenia with obvious symptoms such as fatigue, fever, dizziness, infection and bleeding. This disease has a very rapid onset. Without treatment, a patient only rarely survives more than 6-12 months (Mattiuzzi et al., 2003).

AML is classically subdivided into subtypes L0 through L7 based on the various degrees of differentiation and the lineage of cell maturation using the French-American-British (FAB) classification (Table 1). M1, M2 and M3 leukemia show predominantly granulocytic differentiation and differ from one another in the extent and nature of granulocytic maturation. M4 shows both granulocytic and monocytic differentiation and M5 shows predominantly monocytic differentiation. They are usually monoblast in M5. M6 shows predominantly erythroblastic differentiation and M7 is associated with leukemic megakaryocytes (Bennett et al., 1985).

Acute Lymphocytic Leukemia (ALL): Acute Lymphocytic Leukemia (ALL) also known as acute lymphoblastic leukemia is a cancer of lymphocytes. It is characterized by abnormalities of lymphoid cell precursors, leading to excessive accumulation of leukemic lymphoblasts in the marrow and other organs, in particular the spleen and liver (Mughal and Goldman, 2003). ALL is the most common cancer in children between the ages of 2 and 3 years (Gustafsson et al., 1998). Approximately $85 \%$ of leukemia in children derived from the acute types (Anino et al., 2002; Fitri et al., 2011). Since it affects mainly children, emotion regulation has been identified as one of the key point of consideration during undergoing chemotherapy (Fitri et al., 2011). It also affects adults, mainly those between 30 and 50 years of ages, accounting for $20 \%$ of all adult acute 
Am. J. Immunol., 7 (4): 54-61, 2011

leukemia. The disease is biologically and clinically heterogeneous and the immunophenotypic heterogeneity of ALL gradually emerged with age (Mughal and Goldman, 2003).

The presenting features of ALL are result of the depressed hematopoiesis due to the overgrowth of leukemic cells in the bone marrow. Almost $80 \%$ of patients with ALL have lymphadenopathy. The lymph nodes are usually painless and movable, the spleen and liver are also frequently enlarged, with up to $70-75 \%$ of patients presenting with hepatomegaly and/or splenomegaly. The most common initial symptoms of ALL are attributable to anemia, neutropenia and thrombocytopenia. They are manifested by fatigue, weakness, fever, weight loss and bleeding (Henderson and Afshani, 1990). Rarely, patients may present with respiratory difficulties as a consequence of a mediastinal mass (Mughal and Goldman, 2003).

ALL is divided into subgroups L1-L3 categorized according to the French-American-British (FAB) Classification based on the appearance of the leukemia or blast cells (Table 2). In the subtype L1, the lymphoblast is relatively small with scanty cytoplasm and inconspicuous nucleoli. The lymphoblast is larger with more abundant cytoplasm in the subtype L2. In the subtype L3, the lymphoblast is mature and resembles the Burkitt's-Like leukemia (Mughal and Goldman, 2003).

Chronic Myeloid Leukemia (CML): Chronic Myeloid Leukemia (CML) is also known as chronic myeloid, chronic myelocytic leukemia or chronic granulocytic leukemia. CML is a clonal disease that results from an acquired genetic change in a pluripotential hemopoietic stem cell (Mughal and Goldman, 2003). CML is a myeloproliferative disorder characterized by a biphasic or triphasic clinical course in which a benign chronic phase is followed by transformation into an accelerated and blastic phase (Faderl et al., 1999). It is characterized by the uncontrolled proliferation of granulocytes and usually accompany with proliferation of erythroid cells and megakaryocytes. This disease occurs mainly in adults and very small numbers of children develop this disease (Mughal and Goldman, 2001; Melo and Chuah, 2007).

Common early symptoms of CML are fatigue, tiring easily, weight loss and a sense of fullness in the upper abnormal from an enlarged spleen, which is the most common finding at diagnosis. The swollen spleen (splenomegaly) may fill most of the abdomen.
Table 2: French-American-British (FAB) classification of acute lymphocytic leukemia

\begin{tabular}{ll}
\hline Designation & Description \\
\hline L1 & $\begin{array}{l}\text { The lymphoblasts tend to be small, with little } \\
\text { cytoplasm and regularly shaped nuclei; they are } \\
\text { more mature in appearance than other subtypes } \\
\text { The lymphoblasts appear more immature, } \\
\text { L2 }\end{array}$ \\
Larying in size and nuclear shape \\
The lymphoblasts tend to be large, with \\
abundant cytoplasm and similarly shaped nuclei.
\end{tabular}

(Leonard, 1998)

Headaches, sweating, fever and bone pain or tenderness also may occur. About $90 \%$ of CML patient have a genetic translocation between chromosom 9 and 22 in their leukemic cells called the Philadelphia chromosome $\left(\mathrm{Ph}^{1}\right)$ causes uncontrolled reproduction and proliferation of white blood cells and platelets (Leonard, 1998).

In later stages of the disease, however the leukemic cells lose the ability to mature and blast cells begin to build up in the bone marrow and blood. CML has three distinct phases, the chronic phase, the accelerated phase and the blast phase (or crisis). In the chronic phase (the most common at diagnosis), there are few blast cells and promyelocytes in the blood and bone marrow. This phase may last from several months to several years. More blast cells and fewer normal cells are found in the bone marrow and blood in the accelerated phase. In the blast phase, more than $30 \%$ of the cells in the blood or bone marrow are blast cells. During blast phase, collections of blast cells may form tumors in the bones or lymph nodes (Leonard, 1998).

Transition from the chronic phase to the accelerated and later the blast phase may occur gradually over a year or more, or it may occur abruptly. This new phase is referred to as "blast crisis". Blast crisis occur an average of 3-5 years after diagnosis and is very similar to aggressive acute leukemia but more difficult to treat (Leonard, 1998).

Chronic Lymphocytic Leukemia (CLL): Chronic Lymphocytic Leukemia (CLL) is also known as chronic lymphatic leukemia. CLL typically consists of clonal expansion of mature, long-lived, functionally deficient B-lymphocytes that express high levels of the antiapoptotic protein BCL-2 (Hanada et al., 1993). In 95\% of cases, CLL is a predominantly malignant clonal disorder of B lymphocytes. The remainder is secondary to a T-cell clone. The neoplastic cell is a hypoproliferative, immunologically incompetent small lymphocyte. There is primary involvement of the bone marrow and secondary release into the peripheral blood. The re-circulating lymphocytes selectively infiltrate the lymph nodes, the spleen and he liver (Pepper et al., 1996). 
Am. J. Immunol., 7 (4): 54-61, 2011

Table 3: Rai staging system for chronic lymphocytic leukemia

\begin{tabular}{ll} 
Stage & Description \\
\hline 0 & Absolute lymphocytosis \\
1 & Absolute lymphocytosis and lymphadenopathy \\
2 & Absolute lymphocytosis and splenomegaly or hepatomegaly \\
3 & Absolute lymphocytosis and anemia (hemoglobin $<11 \mathrm{~g} \mathrm{dL}^{-1}$ ) \\
4 & $\begin{array}{l}\text { Absolute lymphocytosis and thrombocytopenia } \\
\text { (platlets }<100000 \mu \mathrm{L}^{-1} \text { ) }\end{array}$ \\
\hline
\end{tabular}

Table 4: Binet Staging System for Chronic lymphocytic leukemia

\begin{tabular}{ll}
\hline Stage & Description \\
\hline A & Two or fewer lymphoid-bearing areas. \\
B & Three or more lymphoid-bearing areas. \\
C & $\begin{array}{l}\text { Presence of anemia (hemoglobin }<10 \mathrm{~g} \mathrm{dL}^{-1} \text { ) and } / o r \\
\left.\text { thrombocytopenia (platlets }<100000 \mu \mathrm{L}^{-1}\right)\end{array}$ \\
\hline
\end{tabular}

(Mughal and Goldman, 2003)

It is the most common type of leukemia in the western word, accounting for more than $30 \%$ of all leukemias, affects people over age of 40 years, but it almost never affects children (Pepper et al., 1996; Mughal and Goldman, 2001).

CLL is primary a disease of the elderly, with the media age of onset being 65 year. Patients with CLL may have general feeling of ill health, fatigue, lack of energy, fever, loss of appetite, night sweats, lymphadenopathy and infection. Some patients have enlarged lymph nodes in the neck or groin showed sign of splenomegaly, anemia, thrombocytopenia or infection (Leonard, 1998). Immunophenotyping is useful in distinguishing B-from T-cell disorders and from a variety of the related lymphoproliferative disorders such as hairy cell leukemia, prolymphocytic leukemia, lymphoplasmacytoid lymphomas and the leukemic phase of follicular non-Hodgkin's lymphoma (Catovsky et al., 1984).

CLL has no standard staging system. The Rai's staging system (Table 3) and the Binet classification (Table 4) are different from the staging used to evaluate other nonleukemic cancers. These systems are based on cytology. One commonly used system known as Rai's staging system (Rai et al., 1975).

Acute Promyelocytic Leukemia (APL): Acute Promyelocytic Leukemia (APL) is a subtype of acute Myelogenous Leukemia (AML) characterized by proliferating abnormal promyelocytes (Kingsley et al., 1987). It is classified as the M3 variant of AML in the internationally accepted French-American-British (FAB) Classification. APL cells are heavily granulated promyelocytes, often with bundles of Auer rods (Mughal and Goldman, 2003). It also occurs in a variant or microgranular form (Golomb et al., 1987).

APL represents approximately $10-15 \%$ of acute myeloid leukemias in adults. The median age is approximately 40 years, which is considerably younger than the other subtypes of AML (Tallman et al., 2002). Most patients with this disorder present with a hemorrhagic diathesis usually associated with Disseminated Intravascular Coagulation (DIC) (Kingsley et al., 1987). Bleeding is usually in the form of petechiae, which correlate the degree of thrombocytopenia or ecchymoses which generally are caused by DIC commonly seen in patients with APL (Tallman et al., 1997).

The human promyelocytic leukemia cells line (HL$60)$ is the derivation of the myeloid cell line HL-60 from the leukemic blood cell population of a 36years old female with Acute Promyelocytic Leukemia (APL) (Gallagher et al., 1979). The HL-60 cell line proliferates continuously in suspension culture with a doubling time of about 36-48 h (Collins et al., 1977).

The cultured HL-60 cells have certain cytologic properties that have been associated with leukemic promyelocytes. These include nuclear/cytoplasmic asynchrony, nuclear bleb formation and heavy azurophilic granulation. The cultured HL-60 cells lack other features that have been described for promyelocytes from some cases of acute promyelocytic leukemia, including morphologically abnormal granules with Auer rod and extensive intracytoplasmic fibril formation and deformation and dilatation of the cisternae of the endoplasmic reticulum (Valdivieso et al., 1975).

These promyelocytes can be induced to differentiate into granulocytes, macrophages or monocytes, eosinophils and basophils by various chemical inducer and culture condition (Matsuhisa and Mori, 1995). Thus, HL-60 cell line provides a unique in vitro model system for studying the cellular and molecular events where aqueous environment, suspended and round cells are needed (Ratanachoo et al., 2002).

Leukemia therapy: Cytotoxic drug and their future: Drug used in the treatment of leukemia represent a wide range of classes with different mode of actions. Until the late 1980s, induction therapy for patients with Acute Promyelocytic Leukemia (APL) was similar to all other patients with Acute Myeloid Leukemia (AML) and included an anthracycline and cytarabine. However, the leukemic cells from patients with APL are peculiarly sensitive to anthracyclines, perhaps because of significantly lower P-glycoprotein (P-gp) expression and other resistance markers in APL cells compared with other subtypes of AML (Lowenberg et al., 2003). Both daunorubicin and idarubicin as single agents induce Complete Remission (CR) in $60-80 \%$ of patients (Witz et al., 1998). 
Current evidence appears compelling that an anthracyline (daunorubicin or idarubicin) should be included in induction in contrast to cytarabine which probably can be omitted (Tallman et al., 2002). Anthracycline (doxorubicin, daunorubicin, idarubicin, mitroxantrone) is a class of antibiotic drugs is regularly used to treat a variety of cancers. Despite their widespread use, their mechanism of action remains unclear. Three postulates exist. Anthracyclines intercalate between DNA base pairs leading to unwinding of the superhelix and interfering with DNA and RNA synthesis, they undergo metabolism to form free radicals and they inhibit topoisomerase II, resulting in DNA strand breakage (Mazzotta et al., 2001).

Note that mitroxantrine is an anthracenedione, an anthracycline-like compound with reduced ability to form free radicals. Daunorubicin, which has a narrower spectrum of utility than doxorubicin, is mainly used in the treatment of acute leukemia. Doxorubicin is used to treat a number of solid tumours as well as multiple myeloma, Hodgkin's disease, non-Hodgkin's lymphoma and acute lymphocytic leukemia. Idarubicin is used in the treatment of acute myeloid leukemia (Mazzotta et al., 2001).

Anthracyclines are metabolized in the liver and excreted in the bile. Dose reduction for patients with decreased liver function is recommended, especially if hyperbilirubinemia is present. Myelosuppression, mucositis and cardiac toxicity are common toxicities of these drugs. Irreversible cardiac toxicity is thought to occur via drug induced oxidative damage by free radicals. The use of lower doses and dexrazoxane (an iron chelator that blocks generation of free radicals) had been shown to prevent cardiac toxicity without loss of antitumour activity. Mitroxantrine causes less cardiotoxicity, nausea and vomiting (Mazzotta et al., 2001).

A recently study has shown that patients with APL fare just as well without cytarabine as part of their induction or consolidation treatment (Sanz et al., 1999). The introduction of All-Trans Retinoic Acid (ATRA) has prompted several study groups to exploit this peculiar sensitivity to anthracyclines by omitting cytarabine during induction. Nevertheless, the evidence appears compelling that cytarabine can be omitted during induction when an anthracycline is given with ATRA. The European APL Group is currently conducting a trial in which patients presenting with a White Blood Cell (WBC) count of $10,000 \mu \mathrm{L}^{-1}$ or fewer are prospectively and randomly assigned to ATRA and daunorubicin or to ATRA plus daunorubicin and cytarabine (Tallman et al., 2002).
Most patients with acute promyelocytic leukemia can be put in complete clinical remission by daily oral administration of all-trans retinoic acid (tretinoin). Side effects include headache, dry skin, xerostomia and itching. Leukocytosis and transient elevation of liver enzymes are often observed. Up to $40 \%$ of patients with APL being treated with ATRA develop a syndrome of fever, respiratory distress, pulmonary infiltrates and effusions. The syndrome is usually reversible with steroid treatment. Because the response to ATRA usually lasts only 3-5 months, with resistance rapidly developing, ATRA is stopped soon after complete remission is achieved and conventional chemotherapy regimens are administered (Warrell et al., 1993).

More recently, there are many types of natural products particularly from plants derived substances possess inhibitory and suppressive effect against leukemic cancer cells. Extracts from plants such as Elephantopus scaber, Vernonia amygdalina, Zingiber zerumbet, Morinda elliptica, Micromelum minutum, Triticum aestivum and Goniothalamus macrophyllus have showed their cytotoxicity and potential to kill various type of leukemic cancer cells (Ho et al., 2009; Yeap et al., 2010b; 2012; Alitheen et al., 2010; 2011; Al-Qubaisi et al., 2011; Saeed and Elias, 2010; Tan et al., 2009; Faujan et al., 2010). Compounds isolated from these plants were found to contribute to the cytotoxicity against leukemic cancer cell. Process of discovering potential natural compounds antileukemia activity can be shorten using Quantitative Structure Activity Relationship (QSAR) study (Pugazhenthi and Rajagopalan, 2009; Saeed and Elias, 2010). Other than direct cytotoxicity, concept of inhibiting the growth of leukemic cancer cell via modulating the immune system by the immunomodulator agents also receiving inadequate attention. Plant extract such as Rhaphidophora korthalsii (Yeap et al., 2011) and compounds isolated from ginger including Zerumbone and Curcumin have found to inhibit leukemic cell lines via stimulation of anticancer cytokines (Yeap et al., 2010a; Gao et al., 2004).

\section{CONCLUSION}

Research direction to discover novel chemotherapy agents for leukemia should focus on identifying natural compounds which carry both cytotoxic and immunomodulatory effects while possess low or no toxicity against normal cell. 


\section{REFERENCES}

Alitheen, N.B., S.K. Yeap, M. Shuhaimi, A.A. Manaf and A.R. Mashitoh et al., 2010. Cytotoxic effect of Damnacanthal, Nordamnacanthal, Zerumbone and Betulinic Acid isolated from Malaysian plant sources. Int. Food Res. J., 17: 711-719.

Alitheen, N.B., C.L. Oon, Y.S. Keong, T.K. Chuan and H.K. Li et al., 2011. Cytotoxic effects of commercial wheatgrass and fiber towards human acute promyelocytic leukemia cells (HL60). Pak. J. Pharm. Sci., 24: 243-250. PMID: 21715255

Al-Qubaisi, M., R. Rozita, S.K. Yeap, A.R. Omar and A.M. Ali et al., 2011. Selective cytotoxicity of goniothalamin against hepatoblastoma HepG2 cells. Molecules, 16: 2944-2959.

Alves, F., D.D.S. Rajao, H.L.D. Puerto, G.F. Braz and R.C. Leite, 2011. Occurrence of feline immunodeficiency virus and feline leukemia virus infection in cats. Am. J. Anim. Vet. Sci., 6: 125129. DOI: $10.3844 /$ ajavsp.2011.125.129

Anino, L., M.L. Vegna and A. Camera, 2002. Treatment of Adult Lymphoblastic Leukemia (ALL): Long-term follow up of the GIMEMA ALL 028 randomized study. Blood, 99: 863-871. PMID: 11806988

Ball, E.D. and A. Kagan, 2007. 100 Questions and Answers about Leukemia. 2nd Edn., Jones and Bartlett Learning, Sudbury, Mass., ISBN: 0763744980, pp: 125.

Becker, W.M., L.J. Kleinsmith and J. Hardin, 2000. The World of the Cell. 4th Edn., The Benjamin Cummings Publishing Co., Inc., California, ISBN: 0805308806, pp: 878.

Bennett, J.M., D. Catovsky, M.T. Daniel, G. Flandrin and D.A. Galton et al., 1985. Proposed revised criteria for the classification of acute myeloid leukemia. A report of the French-American-British cooperative group. Ann. Int. Med., 103: 620-625. PMID: 3862359

Catovsky, D., M. O'Brien and J.V. Melo, 1984. Hairy Cell Leukemia (HCL) variant: An intermediate disease between HCL and B prolymphocytic leukemia. Semin Oncol., 11: 362-369. PMID: 6594759

Collins, S.J., R.C. Gallo and R.E. Gallagher, 1977. Continuous growth and differentiation of human myeloid leukemic cells in suspension culture. Nature, 270: 347-349. PMID: 271272

Darnell, J.E., H. Lodish and D. Baltimore, 1986. Molecular cell Biology. 1st Edn., W.H. Freeman and Compony, New York, pp: 1036.
Evans, C.W., 1991. The Metastatic Cell: Behaviour and Biochemistry. 1st Edn., Chapman and Hall, London, New York, ISBN: 0412303000, pp: 555.

Faderl, S., M. Talpaz, Z. Estrov, S. O'Brien and R. Kurzrock et al., 1999. The biology of chronic myeloid leukemia. Nat. Engl. J. Med., 341: 164172. PMID: 10403855

Faujan, N.H., N.B. Alitheen, S.K. Yeap, A.M. Ali and A.H. Muhajir et al., 2010. Cytotoxic effect of betulinic acid and betulinic acid acetate isolated from Malaysia plant on human myeloid leukemia (HL60) cell line. Afr. J. Biotechnol., 9: 6387-6396.

Fitri, S.Y.R., E.T. Atmodiwirjo and W. Wilman, 2011. Emotion regulation in childhood with cancer (acute lymphocytic leukemia). Am. Med. J., 2: 79-86. DOI: $10.3844 /$ amjsp.2011.79.86

Gallagher, R., S. Collins, J. Trujillo, K. McCredie and M. Aheearn et al., 1979. Characterization of the continuous, differentiating myeloid cell line (HL60) from a patient with acute promyelocytic leukemia. Blood, 54: 713-733. PMID: 288488

Gao, X., J. Kuo, H. Jiang, D. Deeb and Y. Liu et al., 2004. Immunomodulatory activity of curcumin: suppression of lymphocyte proliferation, development of cell-mediated cytotoxicity and cytokine production in vitro. Biochem. Pharmacol., 68: 51-61. PMID: 15183117

Golomb, H.M., A. Fefer and D.W. Golde, 1987. Sequential evaluation of alpha-2b-interferon treatment in 128 patients with hairy cell leukemia. Semin Oncol., 14: 13-17. PMID: 3589701

Gomathi, M. and P. Thangaraj, 2010. A computer aided diagnosis system for lung cancer detection using support vector machine. Am. J. Applied Sci., 7: 1532-1538. DOI: 10.3844/ajassp.2010.1532.1538

Goodman, S.R., 2008. Medical Cell Biology. 3rd Edn., Academic Press, Amsterdam, ISBN: 0123704588, pp: 320.

Gustafsson, G., A. Kreuger, N. Clausen, S. Garwicz and J. Kristinsson et al., 1998. Intensified treatment of acute childhood lymphoblastic leukaemia has improved prognosis, especially in non-high-risk patients: The Nordic experience of 2648 patients diagnosed between 1981 and 1996. Nordic Society of Paediatric Heamatology and Oncology (NOPHO). Acta Paediatr, 87: 1151-1161. PMID: 10342529

Hanada, M., D. Delia, A. Aiello, E. Stadtmauer and J. Reed, 1993. Bcl-2 gene hypomethylation and highlevel expression in B-cell chronic lymphocytic leukemia. Blood, 82: 1820-1828. PMID: 8104532

Henderson, E.S. and E. Afshani, 1990. Clinical Manifestation and Diagnosis. Leukemia, Philadelphia, WB Saunders. 
Ho, W.Y., H. Ky, S.K. Yeap, A.R. Raha and A.R. Omar et al., 2009. Traditional practice, bioactivities and commercialization potential of Elephantopus scaber Linn. J. Med. Plants Res., 3: 1212-1221.

Kingsley, E.C., B.G.M. Durie and H.S. Garewal, 1987. Acute Promyelocytic Leukemia. West J. Med., 146: 322-327. PMID: 3472414

Lee, S.J., K.H. Kim, J.S. Park, D.W. Kim and K.P. Kim, 2007. Comparative analysis of cell surface proteins in chronic and acute leukemia cell lines. Biochem. Biophys. Res. Comm., 357: 620-626. PMID: 17449014

Leonard, B., 1998. Leukemia: A Research Report. 2nd Edn., DIANE Publishing, ISBN: 0788171895, pp: 63.

Lodish, H., 2000. Molecular Cell Biology. 3rd Edn., W.H. Freeman and Compony, New York, ISBN: 0716730537, pp: 1344.

Lowenberg, B., J.R. Downing and A. Burnett, 1999. Acute myeloid leukemia. Nat. Engl. J. Med., 341: 1051-1062.

DOI: 10.1056/NEJM199909303411407

Lowenberg, B., J.D. Griffin and M.S. Tallman, 2003. Acute myeloid leukemia and acute promyelocytic leukemia. Hematology, 1: 82-101. DOI: 10.1182/asheducation-2003.1.82

Matsuhisa, T. and Y. Mori, 1995. Mode of differentiation of human promyelocytic leukemia cell line, HL-60, by $1 \alpha, 25$-Dihydroxyvitamin $\mathrm{D}_{3}$. Blood Cell Mol. Dis., 28: 42-48. PMID: 765586

Mattiuzzi, G.N., G. Alvarado, R. Alvarez, F. Giles, I. Lopez-Roman and E. Estey, 2003. Incidence of pulmonary infiltrates in patients with acute myelogenous leukemia and myelodysplastic syndrome undergoing induction chemotherapy: Retrospective analysis of 5 years. Proceedings of the Abstracts of the 43rd Interscience Conference on Antimicrobial Agents and Chemotherapy, (AAC' 03), American Society for Microbiology, Chicago, pp: 379-379.

Mazzotta, P., A. Kwasnicka and G.J. Kutas, 2001. Cancer chemotherapy: The role of pharmacological agents in the management of hematological malignancies. Univ. Toronto Med. J., 79: 38-45.

Melo, J.V. and C. Chuah, 2007. Resistance to imatinib mesylatate in chronic myeloid leukemia. Cancer Lett., 249: 121-132. PMID: 16949736

Mughal, T.I. and J.M. Goldman, 2001. Chronic myeloid leukaemia. STI 571 magnifies the therapeutic dilemma. Eur. J. Cancer, 37: 161-168. PMID: 11290430
Mughal, T.I. and J.M. Goldman, 2003. Chronic Myeloid Leukaemia. Eur. J. Cancer, 37: 561-568.

Pepper, C., P. Bentley and T. Hoy, 1996. Regulation of clinical chemoresistance by bcl-2 and baxoncoproteins in B-cell chronic lymphocytic leukemia. Br. J. Heamatol., 95: 513-517. PMID: 8943893

Pugazhenthi, D. and S.P. Rajagopalan, 2009. Unbalance quantitative structure activity relationship problem reduction in drug design. J. Comput. Sci., 5: 764772. DOI: $10.3844 /$ jcssp.2009.764.772

Rai, K.R., A. Sawitsky, E.P. Cronkite, A.D. Chanana and R.N. Levy et al., 1975. Clinical staging of chronic lymphocytic leukemia. Blood, 46: 219234. PMID: 1139039

Ratanachoo, K., P.R. Gascoyne and M. Ruchirawat, 2002. Detection of cellular responses to toxicants by dielectrophoresis. Biochim. Biophys. Acta, 1564: 449-458. PMID: 12175928

Saeed, B.A. and R.S. Elias, 2010. Density functional theory based quantitative structure activity relationship study of 2,5-Bis(1-Aziridinyl)-pbenzoquinones with lymphoid leukemia. Am. J. Applied Sci., 7: 902-905. DOI: 10.3844/ajassp.2010.902.905

Sanz, M.A., G. Martin, C. Rayon, J. Esteve and M. Gonzalez et al., 1999. A modified AIDA protocol with anthracycline based consolidation results in high anti-leukemic efficacy and reduced toxicity in newly diagnosed acute promyelocytic leukemia. Blood, 94: 3015-3021. PMID: 10556184

Tallman, M.S., J.W. Andersen and C.A. Schiffer, 1997. All-trans retinoic acid in acute promyelocytic leukemia. Nat. Engl. J. Med., 337: 1201-1208. PMID: 9321529

Tallman, M.S., C.H. Nabhan, J.H. Feusner and J.M. Rowe, 2002. Acute promyelocytic leukemia: Evolving therapeutic strategies. Blood, 99: 759767. PMID: 11806975

Tan, B.K., N.B. Alitheen, S.K. Yeap, A.M. Ali and R. Mawardi, 2009. Cytotoxic effect of 2',3'-epoxy isocapnolactone and 8-hydroxyisocapnolactone2'3'-diol isolated from Micromelum minutum (G.Forst.) Wight and Arn. in human T-lymphocyte leukemia CEM-SS cells. Afr. J. Biotechnol., 8: 4632-4641.

Valdivieso, F., C. Gimenez and F. Mayor, 1975. In vivo inhibition of rat liver phenylalanine hydroxylase by p-chlorophenylalanine and esculin: Experimental model of phenylketonuria. Biochem. Med., 12: 7278. PMID: 124571 
Warrell, R.P. Jr., H.D. The, Z.Y. Wang and L. Degos, 1993. Acute promyelocytic leukemia. Nat. Engl. J. Med., 329: 177-189. DOI: 10.1056/NEJM199401133300213

Witz, F., A. Sadoun, M.C. Perrin, C. Berthou and J. Briere et al., 1998. A placebo-controlled study of recombinant human granulocyte-macrophage colony-stimulating factor administered during and after induction treatment for de novo acute myelogenous leukemia in elderly patients. Groupe Ouest Est Leucemies Aigues Myeloblastiques (GOELAM). Blood, 91: 2722-2730. PMID: 9531581

Yeap, S.K., N.B. Alitheen, S. Mustafa, A.S. Abdul and R.M. Abdul et al., 2010a. Immunomodulatory effects of zerumbone isolated from roots of Zingiber zerumbet. Pak. J. Pharm. Sci., 23: 75-82.
Yeap, S.K., W.Y. Ho, B.K. Beh, W.S. Liang and H. Ky et al., 2010b. Vernonia amygdalina, an ethnoveterinary and ethnomedical used green vegetable with multiple bio-activities. J. Med. Plants Res., 4: 2787-2812.

Yeap, S.K., N.B.M. Alitheen, W.Y. Ho, A.R. Omar and A.M. Ali et al., 2011. Immunomodulatory role of Rhaphidophora korthalsii methanol extract on human peripheral blood mononuclear cell proliferation, cytokine secretion and cytolytic activity. J. Med. Plants Res., 5: 958-965.

Yeap, S.K., A.R. Omar, A.M. Ali, W.Y. Ho and B.K. Beh et al., 2012. Immunomodulatory effect of Rhaphidophora korthalsii on natural killer cell cytotoxicity. Evid Based Complement Alternat Med., 2012, 786487-786487. PMID: 3175394 